\title{
PARA O ESTUDO DA DENOMINAÇÃO DOS CONJUNTOS EM PORTUGUÊS - Aspectos morfo-semânticos dos nomes dos colectivos
}

Margarita Correia*

RESUMO: Com este artigo pretendo contribuir para o estudo da denominação dos conjuntos em português europeu. No entanto, ele não pode ser considerado um trabalho exaustivo sobre este tema. Dado considerar a estrutura das palavras fundamental para a compreensão do seu significado e uso, prestarei particular atenção a este aspecto dos substantivos colectivos.

Em primeiro lugar, exporei de modo breve o conceito de substantivo colectivo, tendo em especial atenção Cunha \& Cintra (1984). Em seguida, descreverei os diferentes tipos de estruturas morfológicas das palavras que podem apresentar acepções colectivas. Finalmente listarei os sufixos envolvidos na construção de substantivos colectivos denominais em português.

Palavras-chave: formação de palavras em português, substantivos colectivos, substantivos denominais, deadjectivais, deverbais, polissemia.

"Uma coisa que nos poderiam ter dito na escola (mas, em geral, não disseram) é para quê a gente precisa separar as palavras em classes. Ora, a razão é semelhante à que nos obriga a separar os animais em classes, ordens, espécies etc.: classificamos as palavras para podermos tratar delas com um mínimo de economia."

Perini (1997, p. 41)

\section{INTRODUÇÃO}

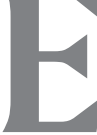

ntre a classe dos substantivos, as gramáticas de língua portuguesa delimitam a subclasse dos substantivos colectivos, definindo-os genericamente como substantivos que, estando no singular, denotam conjuntos de entidades.

Constituindo embora uma parte significativa dos substantivos do português, esta subclasse de palavras não tem sido alvo da atenção 
CORREIA, Margarita. Para o estudo da denominação dos conjuntos em português - Aspectos morfo-semânticos dos nomes dos colectivos.

merecida da parte de linguistas em geral e de lexicólogos em particular. Com este trabalho, pretendo, pois, contribuir para o estudo dos substantivos colectivos, chamando a atenção para a estrutura que estas palavras podem apresentar, factor que considero fundamental para a descrição do seu funcionamento.

Deste modo, após uma breve apresentação do conceito de 'substantivo colectivo' tal como ele é apresentado particularmente em Cunha \& Cintra (1984) ${ }^{1}$, irei descrever sumariamente os diversos tipos de estruturas morfológicas exibidos pelos substantivos colectivos. Por fim, deter-me-ei particularmente na listagem dos sufixos que permitem a construção de substantivos denominais colectivos; terei em conta, sobretudo, a variante europeia do português. Os dados apresentados neste artigo não poderão, no entanto, ser considerados nem exaustivos nem definitivos, dado que o tema merece uma investigação bastante mais aprofundada que apenas agora começa a ser feita - cf. Bojilova (em preparação).

A análise tem por fundamentação teórica o modelo de morfologia derivacional associativo e estratificado desenvolvido por Danielle Corbin (cf. bibliografia) e pela equipa de investigadores do SILEX (UMR do CNRS, Universidade de Lille, França).

\section{O CONCEITO DE "NOME COLECTIVO"}

No capítulo consagrado à classe dos nomes, Cunha \& Cintra definem os substantivos colectivos do seguinte modo:

"Colectivos são os substantivos comuns que, no singular, designam um conjunto de seres ou coisas da mesma espécie." (1984, p. 178).

Em Aliquot-Suengas (1996) e Solé Solé (1996) podem encontrar-se descrições mais detalhadas deste conceito. 
Tendo em conta a referência dos substantivos colectivos, estes autores estabelecem quatro tipos distintos destes substantivos consoante eles refiram a:

i. um todo - ex.: povo (o povo brasileiro);

ii. uma parte organizada de um todo - ex.: regimento, $b a$ talhão, companhia (partes do colectivo que é o exército);

iii. um grupo acidental - ex.: grupo, multidão, bando (bando de andorinhas, bando de ciganos, bando de salteadores);

iv. um grupo de seres de determinada espécie - ex.: boiada (de bois), ramaria (de ramos) ${ }^{2}$.

(cf. Cunha \& Cintra, 1984, p. 178-9).

Cunha \& Cintra excluem da subcategoria dos colectivos "os nomes de corporações sociais, culturais e religiosas, como assembleia, congresso, congregação, concilio, conclave e consistório", porque, segundo eles, tais substantivos não denominam "simples agrupamentos de seres, antes representam instituições de natureza especial, organizadas em uma entidade superior para determinado fim" (1984, p. 179) - este argumento, porém, não parece parece muito claro, sobretudo se forem tidos em conta os exemplos apresentados no tipo ii. acima referido.

As únicas referências feitas, nesta rubrica, a substantivos colectivos derivados são indirectas e surgem em duas notas:

a) informam os autores excluir da lista dos colectivos os numerais colectivos como novena, década, dúzia, remetendo-nos para o capítulo referente aos numerais;

b) referem a omissão obrigatória da referência às pessoas ou coisas a que se referem, "quando o colectivo é um mero derivado do substantivo a que se aplica" e dão como exemplos: " $A$ ramaria balouçava ao vento. / A papelada estava em ordem."

(cf. Cunha \& Cintra, 1984, p. 180, observações $1^{\mathrm{a}}$ e $2^{\mathrm{a}}$ ).

2 Retenho os exemplos dados pelos próprios autores. 
CORREIA, Margarita. Para o estudo da denominação dos conjuntos em português - Aspectos morfo-semânticos dos nomes dos colectivos.

Outras referências aos substantivos colectivos, encontrá-las-emos, nesta gramática, no capítulo destinado à formação de palavras. O quadro I apresenta um apanhado dos sufixos apresentados em Cunha \& Cintra (1984, p. 96-7), que permitem construir substantivos denominais. São apresentados aqui apenas aqueles sufixos que, segundo os autores, permitem a construção de colectivos.

Quadro I

\begin{tabular}{|l|l|l|}
\hline Sufixo & Sentido & Exemplificação \\
\hline -ada & a) multidão colecção & boiada, papelada \\
\hline -agem & a) noção colectiva & folhagem, plumagem \\
\hline -al & c) noção colectiva ou de quantidade & areal, pombal \\
\hline -alha & colectivo-pejorativo & canalha, gentalha \\
\hline -ama & noção colectiva e de quantidade & dinheirama, mourama \\
\hline -ame & noção colectiva e de quantidade & vasilhame, velame \\
\hline -aria & b) noção colectiva & gritaria, pedraria \\
\hline -edo & noção colectiva & olivedo, vinhedo \\
\hline -eiro(a) & f) noção colectiva & barreiro, formigueiro \\
\hline -ia & c) noção colectiva & cavalaria, clerezia \\
\hline -io & noção colectiva, reunião & gentio, mulherio \\
\hline -ume & noção colectiva e de quantidade & cardume, negrume \\
\hline
\end{tabular}

Sem querer alargar-me na discussão do tratamento conferido aos colectivos nesta gramática ${ }^{3}$, algumas observações parecem-me, no entanto, necessárias:

3 Em I. Bojilova (em preparação) encontrar-se-á uma análise mais detalhada do tratamento dado a estes substantivos em gramáticas portuguesas. 
1. São sobretudo critérios de índole referencial os mais relevantes para a definição de 'colectivo', o que é frequente na delimitação das subcategorias de substantivos ${ }^{4}$. No entanto, os critérios usados na delimitação dos diferentes tipos de colectivos não parecem os mais pertinentes $^{5}$, facto que fica evidenciado, por exemplo na delimitação do quarto destes tipos (apresentado como constituído pelos colectivos que referem a "um grupo de seres de determinada espécie - ex.: boiada (de bois), ramaria (de ramos)" - Cunha \& Cintra (1984, p. 179) -, quando anteriormente toda a subcategoria havia sido definida como sendo constituída pelos substantivos que designam "um conjunto de seres ou coisas da mesma espécie.” (1984, p. 178).

2. No Quadro I, é visível o tipo de tratamento semântico conferido por esta gramática aos sufixos: a estes é atribuído significado de tipo lexical, de modo que não se distingue entre o significado do afixo (que é de carácter instrucional ${ }^{6}$, de acordo com o modelo de análise usado) e o significado do derivado, esse sim de tipo lexical, produto do significado da base, do significado conferido pela regra de formação de palavras e, ainda, pelo significado do afixo em causa.

3. Entre os exemplos de colectivos derivados por sufixação apresentados no Quadro I, surgem alguns substantivos que, mais do que colectivos, são efectivamente intensificadores - dinheirama e negrume não constitutem colectivos dado que as suas bases (dinheiro e negro) não denominam entidades contáveis, condição sine qua non para possibilitar a construção do significado colectivo num substantivo denominal.

4 Notem-se os critérios normalmente usados para a distinção entre substantivos abstractos e concretos, por exemplo.

5 Em M. Correia (no prelo) apresento alguns critérios de índole referencial a meu ver mais pertinentes para a delimitação de subtipos de substantivos colectivos.

6 O 'significado instrucional' não permite às unidades referir, mas permite-lhes ajudar outras unidades a referirem, ou permite configurar a referência destas unidades de uma determinada maneira. São portadoras de significado apenas instrucional as preposições, as conjunções, os conectores frásicos, alguns advérbios, os determinantes e os pronomes, e os afixos (flexionais e derivacionais). O significado instrucional não é, pois, representável sob a forma de enumeração de um conjunto de propriedades referenciais, mas pode ser concebido como um modo de utilização da unidade (cf. Corbin, a publicar). 
CORREIA, Margarita. Para o estudo da denominação dos conjuntos em português - Aspectos morfo-semânticos dos nomes dos colectivos.

4. - Alha é indevidamente referido como sendo passível de construir substantivos colectivos. De resto, esse facto torna-se patente nos próprios exemplos de derivados apresentados: canalha não é uma palavra construída em português (provém do italiano canaglia), ao passo que, em gentalha, o "sentido" colectivo é herdado da base (gente) e não do sufixo.

\section{ESTRUTURAS MORFOLÓGICAS DOS SUBSTANTIVOS COLECTIVOS}

Os substantivos que em português permitem denominar entidades colectivas podem apresentar uma das seguintes estruturas:

- podem ser palavras simples - exs.: vara, alcateia, bando, grupo;

- podem ser palavras complexas não construídas, isto é, palavras que, embora exibindo uma certa estrutura interna formal e semântica, não preenchem todas as condições para que essa estrutura seja identificada à de uma palavra construída, ou porque a sua base aparente não preenche todos os requisitos definidos para a delimitação das bases, ou porque o seu significado não é compatível com a estrutura que lhes é atribuível em função da operação derivacional da qual, aparentemente, são o produto ${ }^{7}$ - exs.: canalha, partitura e comissão, procedentes, respectivamente, do italiano canaglia, partitura e do latim comissione-;

- podem ser palavras construídas, isto é, unidades cujo significado, forma e/ou estrutura resultam de uma ou várias operações linguísticas, apresentando motivação recíproca entre a forma (e/ou a estrutura) e o significado (cf. Corbin, 1997, p. 7).

Para efeitos do presente trabalho, apenas serão tomadas em conta, daqui em diante, as palavras construídas. Entre elas, podem distinguir-se três tipos de estruturas distintas: nomes deverbais, nomes deajectivais e nomes denominais.

Cf. Corbin (1987, p. 455-65). 
Como exemplos de nomes deverbais que podem exibir acepções colectivas, poderão referir-se abotoadura, encorreadura, pregadura, direç̧ão, ondulação, prostituição, tripulação e, ainda, caibramento, equipamento, travejamento. Qualquer destes substantivos (primeiramente nomes de acção e, portanto, nomes abstractos) para além de "aç̧ão ou o efeito de $\mathrm{Vb}$ "

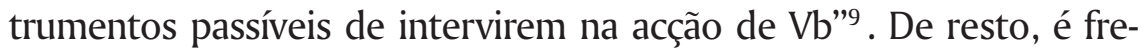
quente os nomes de acção se tornarem polissémicos, passando a denominar um dos actantes de $\mathrm{Vb}^{10}$, pelo processo a que R. Martin chama "concretização actancial" (cf. Martin, 1996, p. 50).

Os substantivos deadjectivais que exibem acepções colectivas são, sobretudo, substantivos em -(i)dade e, ainda, em -ismo, tais como catolicidade, cristandade, humanidade, convencionalismo, protestantismo, ritualismo ${ }^{11}$. Estes substantivos são basicamente nomes abstractos: nomes de qualidade, no caso dos que exibem -(i)dade, nomes de qualidade ou nomes de ideologias / sistemas políticos, filosóficos, etc., no caso daqueles que apresentam -ismo. A acepção colectiva é derivada a

8 "Vb" representa "verbo base (de derivação)".

9 Segundo DLP, abotoadura: «conjunto ou jogo de botões para uma peça de vestuário»; encorreadura: «conjunto de correias aplicadas a um determinado fim»; pregadura: "conjunto dos pregos que seguram ou adornam uma peça»; direç̧ão: «conjunto dos directores de um estabelecimento»; ondulação: «conjunto das elevações e depressões de uma superfície»; prostituição: "conjunto das prostitutas»; tripulação "conjunto das pessoas empregadas no serviço de um navio ou de um avião»; caibramento: "conjunto dos caibros de um telhado»; equipamento: "conjunto de meios mecânicos ou industriais de uma empresa, de uma região, de um país»; travejamento: "conjunto das traves de um edifício».

DLP - Costa, J. Almeida \& A. Sampaio e Melo (1994) (cf. bibliografia). Salvo indicação em contrário, as definições lexicográficas apresentadas no presente artigo (assinaladas com aspas «») são extraídas deste dicionário.

10 Exemplos de concretizações actanciais são, segundo R. Martin, construção: "aquilo que se constrói” (actante objecto); paragem: "local onde X pára" (actante local); vereação: "tempo durante o qual X vereia” (actante tempo) (cf. Martin, 1996, p. 50).

11 Catolicidade: «o conjunto dos católicos»; cristandade: «conjunto de todos os cristãos»; humanidade: "o conjunto de todos os homens»; convencionalismo: «sistema ou conjunto de convenções»; protestantismo: «conjunto das confissões cristãs, dissidentes do catolicismo, e nascidas da Reforma religiosa, movimento separatista do século XVI; (...) conjunto dos protestantes»; ritualismo: «conjunto dos ritos de uma igreja». 
CORREIA, Margarita. Para o estudo da denominação dos conjuntos em português - Aspectos morfo-semânticos dos nomes dos colectivos.

partir do seu significado estrutural ("qualidade de Adjb"12) e é parafraseável por "conjunto de todas as entidades que exibem de modo suficientemente relevante a qualidade denominada por Adjb". Frequentemente, o Adjb denomina uma qualidade suficientemente relevante para a constituição de uma categoria e, por isso, por conversão de focalização ${ }^{13}$, vai permitir a construção de um substantivo que pode denominar cada um dos seus membros $\left(\right.$ católico $_{\mathrm{N}}$ cristão $_{\mathrm{N}}$, humano ${ }_{\mathrm{N}}$, protestante $_{\mathrm{N}}$ ritual $_{\mathrm{N}}{ }^{14}$ ).

Do mesmo modo que em relação aos nomes deverbais se pôde falar em 'concretização actancial', também aqui se poderá falar, ainda segundo os termos de R. Martin, em concretização objectal: aquela que conduz da propriedade ao objecto que a possui ${ }^{15}$ (cf. Martin, 1996, p. 50).

Entre os substantivos denominais, é possível distinguir três subconjuntos de substantivos. No primeiro destes subconjuntos, contam-se alguns nomes como eleitorado, internato, clerezia ${ }^{16}$, cujo significado estrutural básico é parafraseável por "condição / estatuto de $\mathrm{Nb}^{17}$ ", fazendo parte, portanto, dos chamados 'nomes de estatuto ou condição'; neles, o significado colectivo é construído a partir do significado estrutural e é parafraseável por "todos aqueles que apresentam a condição / o estatuto de $\mathrm{Nb}{ }^{\prime 18}$.

12 "Adjb" representa "adjectivo base (de derivação)".

13 A conversão de focalização consiste em denominar uma categoria referencial através de uma das suas características, expressa pelo adjectivo de base - exs.: fino $_{\mathrm{Adj}}>$ fino $_{\mathrm{N}}$ (copo de cerveja); eléctrico $_{\mathrm{Adj}}>$ eléctrico $_{\mathrm{N}}$ (meio de transporte) (cf. Corbin, D. \& P., 1991, p. 77-8).

14 Não analisei o caso de convencionalismo $<$ convencional $<$ convenção, que foge ao padrão apresentado.

15 Como exemplos de concretização objectal, poder-se-ão mencionar beleza (denominando um indivíduo que se destaca por ser belo) ou palermice (denominando uma frase, uma atitude ou um comportamento palerma).

16 Segundo DLP: eleitorado: «conjunto dos eleitores»; internato: «conjunto dos indivíduos internos»; clerezia: «classe clerical; o clero».

17 "Nb" representa "nome (substantivo) base (de derivação)".

18 Estes substantivos comportam-se de forma bastante semelhante aos nomes de qualidade referidos anteriormente. De resto, sendo discutível se as suas bases são substantivos ou 
Num segundo grupo, poderão incluir-se alguns nomes locativos, parafraseáveis muito genericamente por "local onde existe $\mathrm{Nb}$ (em grande quantidade)". Frequentemente, quando a base destes substantivos designa uma entidade concreta e contável que se encontra em grande quantidade no local designado pelo derivado, este pode exibir o significado de "conjunto (grande quantidade) de Nb" - exs. mealheiro, tortulheira, colmeal, parreiral, receituário. ${ }^{19}+20$

Em qualquer dos subgrupos anteriormente definidos (nomes deverbais, nomes deadjectivais e nomes denominais de estatuto/condição ou locativos), o significado colectivo apresenta-se como um significado secundário em relação ao significado estrutural dos substantivos em causa. Poderá falar-se nestes casos em 'polissemia sistemática' ('polysémie systématique'), no sentido que lhe é atribuído por Nunberg e Zaenen $(1997)^{21}$; restará, no entanto, determinar com precisão as condições para que essa transferência de significado seja possível, isto é, a que condições (morfológicas, semânticas, referenciais) deverá obedecer uma determinada palavra para que seja possível ela tornar-se polissémica.

Finalmente, em terceiro lugar, resta referir o caso dos substantivos denominais cujo primeiro significado, directamente relacionado

adjectivos, pode pensar-se se não seria mais profícuo inserir uns e outros, nomes de qualidade e nomes de estatuto / condição, numa macro-regra de formação de palavras cujas bases poderão ser consideradas nomes predicativos, na linha do proposto por RioTorto (1992a). Em Correia (em preparação) são discutidas estas questões.

19 Mealheiro: «caixinha onde se vai guardando o dinheiro que se deseja economizar; conjunto de mealhas»; tortulheira: «(reg.) viveiro de tortulhos; conjunto de hastes ou rebentos saídos da raiz de uma só planta»; colmeal: «lugar onde estão colmeias; conjunto de colmeias»; parreiral: «lugar onde há parreiras; conjunto de parreiras»; receituário: «livro onde se indicam as fórmulas dos medicamentos, doses aplicáveis, etc.; conjunto de receitas que o médico prescreve durante uma doença (...)».

20 Sobre a construção de nomes locativos, cf. Piel (1944) e Rio-Torto (1986) e (1992b).

21 Por 'polissemia sistemática' entende-se o facto de ser possível fazer generalizações produtivas a propósito das diferentes utilizações de uma determinada palavra, sob a forma de asserções condicionais do tipo: «Se uma palavra tem uma utilização do tipo $s$, tem também uma utilização do tipo s'». Como exemplo, uma palavra que designa um local, pode ser usada para fazer referência aos seus habitantes (cf. Nunberg \& Zaenen, 1997, p. 12). 
CORREIA, Margarita. Para o estudo da denominação dos conjuntos em português - Aspectos morfo-semânticos dos nomes dos colectivos.

com a sua estrutura, é o significado colectivo. Trata-se de derivados por sufixação, gerados por uma mesma regra de formação de palavras, de cujo paradigma afixal fazem parte os seguinte sufixos:

-ada (exs.: brasileirada, papelada), -agem (exs.: ciganagem, plumagem),

-ama (ex.: mourama), -ame (ex.: vasilhame, velame), -aria (exs.:

folharia, pedraria), -edo (exs.: arvoredo, passaredo), -io (exs.: rapazio, mulherio).

A lista apresentada não pode ser considerada exaustiva; não se exclui a possibilidade de alguns outros sufixos nominais poderem vir a revelar-se como basicamente pertencentes ao paradigma afixal desta regra.

Por outro lado, muitos dos derivados com alguns destes afixos evidenciam frequentemente também significados secundários que tornam a delimitação entre as diferentes regras de formação de substantivos e os seus respectivos produtos extremamente problemática ${ }^{22}$ - é o caso, por exemplo, dos derivados em -ada, -agem e -aria, quando as suas bases denominam entidades humanas, em que, a par do significado colectivo, surgem acepções parafraseáveis por "o facto de ser $\mathrm{Nb} /$ comportamento / atitude / dito estereotipicamente atribuído a Nb" (cf. americanada, ciganagem, judiaria ${ }^{23}$ ).

\section{NOTAS CONCLUSIVAS}

Ao longo do presente trabalho, pretendeu-se dar conta dos diferentes tipos de estruturas apresentadas por palavras que, entre as suas diferentes acepções, apresentam significações colectivas, sendo, pois,

22 'Esta dificuldade tem sido, de resto, repetidamente evidenciada nos diferentes trabalhos de Rio-Torto.

23 Americanada: «conjunto de americanos; americanice»; ciganagem: «multidão de ciganos; acto de cigano; trapaça; trapaça; ciganice; ciganaria»; judiaria: "grande número de judeus; bairro de judeus; (fig.) diabrura; travessura; maldade; maus tratos». 
passíveis de denominar conjuntos, mais ou menos organizados, de entidades da mesma espécie. As palavras simples e as palavras complexas não-construídas não foram alvo de análise detalhada, dado que um dos principais pressupostos que fundamentam este trabalho é o de que existe uma relação incontornável entre a estrutura, por um lado, e o significado e a referência das palavras construídas, por outro.

Verificou-se, então, que, além dos substantivos denominais primeiramente colectivos (isto é, aqueles que como significado estrutural apresentam o parafraseável por "conjunto de $\mathrm{Nb}$ ”), outros substantivos podem apresentar este tipo de acepções: alguns nomes de acção (deverbais), alguns nomes de qualidade ou de ideologias, etc. (deadjectivais) e, entre os denominais, alguns nomes de estatuto/condição e alguns locativos. Ficaram, no entanto, por estabelecer as condições em que as transferências de significado verificadas podem ocorrer, embora se tenham dado algumas indicações nesse sentido.

A apresentação agora feita carece de análises mais aprofundadas, sendo, apenas, uma primeira proposta de abordagem do tema.

\section{BIBLIOGRAFIA}

ALIQUOT-SUENGAS, S. (1996) Référence collective / sens collectif: la notion de collectif à travers les noms suffixés du lexique français. Tese de Doutoramento. Universidade de Lille III (inédita).

BOJILOVA, I. (em preparação) A formação dos nomes colectivos em português. Tese de doutoramento. Lisboa, Faculdade de Letras da Universidade de Lisboa.

CARVALHO, J. G. H. de (1983) Substantivo. In Enciclopédia Luso-Brasileira de Cultura. v. 17. Lisboa, Verbo, p. 746-7.

CORBIN, D. (1987) Morphologie dérivationnelle et structuration du lexique. 2 v. Tubinga, Max Niemeyer Verlag.

(1991) Introduction - La formation des mots: structures et interprétations. Lexique 10. Villeneuve d'Ascq, Presses Universitaires de Lille, p. 7-30.

(1997) La réprésentation d'une "famille" de mots dans le Dictionnaire dérivationnel $d u$ français et ses corrélats théoriques, méthodologiques et descriptifs. In Recherches linguistiques de Vincennes, p. 5-37 + errata.

(a publicar) Le lexique construit. Paris, Armand Colin. 
CORREIA, Margarita. Para o estudo da denominação dos conjuntos em português - Aspectos morfo-semânticos dos nomes dos colectivos.

; CORBIN, P. (1991) Un traitement unifié du suffixe -ier(e). Lexique 10. Villeneuve d'Ascq, Presses Universitaires de Lille, p. 61-145.

CORREIA, M. (no prelo) Os substantivos colectivos em português - aspectos da construção do seu significado. Actas do VI Simpósio Ibero-Americano de Terminologia (Havana, Novembro de 1998).

(em preparação) A formação dos nomes de qualidade em português. Dissertação de Doutoramento a apresentar à Faculdade de Letras da Universidade de Lisboa.

COSTA, J. A.; SAMPAIO E MELO, A. (1994) Dicionário da Língua Portuguesa. 7. ed. revista e ampliada. Porto, Porto Editora.

CUNHA, C.; CINTRA, L. F. L. (1984) Nova gramática do português contemporâneo. Lisboa, Edições João Sá da Costa.

ELIA, S. (1984) Nome. In Enciclopédia Luso-Brasileira de Cultura. v. 14. Lisboa, Verbo, p. 202.

MARTIN, R. (1996) Le fantôme du nom abstrait. In FLAUX, N.; GLATIGNY, M.; SAMAIN, D. (eds.) Les noms abstraits, histoire et théories. Villeneuve d'Ascq, Presses Universitaires du Septentrion, p. 41-50.

NUNBERG, G.; ZAENEN, A. (1997) La polysémie systématique dans la description lexicale. Langue Française, 113, p. 12-23.

PERINI, M. (1997) Sofrendo a gramática. São Paulo, Ática.

PIEL, J. (1944) A formação dos nomes de lugares e de instrumentos em português. Boletim de Filologia, tomo VII, p. 31-47.

RIO-TORTO, G. M. (1986) Contribuição para o estudo da especificidade morfo-lexical dos sufixos: os sufixos -aria. Biblos v. LXII, p. 305-63.

. (1987) Morfologia das palavras construídas em -ad(a). Biblos v. LXIII, p. 97-178.

(1992a) Do ser à acção: "o facto de ser x", "atitude de (quem é) x" e "condição (estatuto) de x". Separata da Revista da Universidade de Coimbra, vol. de homenagem a Luís de Albuquerque, p. 427-56.

. (1992b) Para uma teoria da formação de palavras em português: análise dos locativos não-deverbais. Actas do XIX Congreso Internacional de Lingüística e Filoloxía Románicas (Santiago de Compostela, 1989), v. V. A Coruña, Fundación "Pedro Barrié de la Maza, Conde de Fenosa", p. 869-91.

. (1994) Regras de formação de palavras em português: achegas para um quadro geral. Diacrítica, 9, p. 319-42.

SOLÉ SOLÉ, E. (1996) Morfologia Lèxica: els noms colllectius - reconeixement en diccionaris de llengua general. Trabalho de pesquisa. Barcelona, Institut Universitari de Linguiística Aplicada / Universidade Pompeu Fabra (inédito).

ABSTRACT: With this paper I intend to contribute to the study of collective denomination in European Portuguese. However it can not be considered an exhaustive work on this subject. As I consider the structure of words fundamental to understand their meaning and use, I'll pay special attention to this aspect of collective nouns. 
Filologia e Lingüística Portuguesa, n. 3, p. 9-21, 1999.

Firstly, I'll expose, although briefly, the concept of "collective noun", specially as it is presented at Cunha \& Cintra (1984). Then the different types of morphological structures of nouns presenting a collective meaning will be described. Finally, I'll list the suffixes involved in the construction of Portuguese collective denominal nouns.

Keywords: collective nouns, Portuguese word-formation, denominal, deadjectival, denominal nouns, polysemy. 